Pesq. Vet. Bras. 37(7):749-753, julho 2017

DOI: $10.1590 / \mathrm{S} 0100-736 \mathrm{X} 2017000700016$

\title{
Paratuberculosis: new histopathological findings in red deer (Cervus elaphus) and fallow deer (Dama dama) in Chile ${ }^{1}$
}

\author{
Esteban Reyes Lobão-Tello², Enrique Paredes Herbach ${ }^{2}$ \\ and María José Navarrete-Talloni ${ }^{2 *}$
}

\begin{abstract}
Lobão-Tello E.R., Herbach P.E. \& Navarrete-Talloni M.J. 2017. Paratuberculosis: new histopathological findings in red deer (Cervus elaphus) and fallow deer (Dama dama) in Chile. Pesquisa Veterinária Brasileira 37(7):749-753. Unidad de Anatomía Patológica, Instituto de Patología Animal, Facultad de Ciencias Veterinarias, Universidad Austral de Chile, Isla Teja, Valdivia, Chile.E-mail: majose.navarrete@uach.cl

Paratuberculosis is a disease caused by Mycobacterium avium subsp. paratuberculosis (MAP) that affects domestic and wild ruminants. The most common gross lesions are emaciation and corrugation and thickening of the mucosa of the small intestine. Mesenteric lymph nodes might be enlarged. For the present study, 14 red deer and 9 fallow deer from game reserves or venison farms were analyzed. The lesions found correspond to those found by other authors in other geographic locations, except for some differences in histopathological examinations. Among these differences, stands out that intestinal lesions were concentrated mostly in the ileum and granulomas were shown to be more frequent in this section of the intestine than in the corresponding lymph node. Furthermore, in multibacillary lesions the inflammatory infiltrate in the lymph nodes was mainly composed of macrophages. These differences may be due to individual variations of the animals, the stage of disease or a different strain of the pathogen. This study allowed to obtain basic information about the disease and to describe patterns of lesions found in red deer and fallow deer with prediagnosis of clinical paratuberculosis which were not described in the literature before.
\end{abstract}

INDEX TERMS: Red deer, Cervus elaphus, fallow deer, Dama damam, Mycobacterium avium, pratuberculosis, deer, MAP.

RESUMO.- [Paratuberculosis: novos achados histopatológicos em Veado Vermelho (Cervus elaphus) e Gamo (Dama dama) no Chile.] Paratuberculosis é uma doença causada por Mycobacterium avium subsp. paratuberculosis (MAP) que afecta ruminantes selvagens e domésticos. As lesões macroscópicas mais comuns são ondulação e espessamento da mucosa do intestino delgado. Os linfonodos mesentéricos podem aparecer com volume aumentado. Para este estudo, foram analisados 14 veados vermelhos e 9 veados gamo de reservas de caça e fazendas de carne. As lesões encontradas correspondem à encontrada por outros autores em outras localizações geográficas, com exceção de algumas diferenças no exame histopatológico. Entre essas

\footnotetext{
${ }^{1}$ Received on July 18, 2016.

Accepted for publication on January 11, 2017.

${ }^{2}$ Unidad de Anatomía Patológica, Instituto de Patología Animal, Facultad de Ciencias Veterinarias, Universidad Austral de Chile, Isla Teja, Valdivia, Chile. *Corresponding author: majose.navarrete@uach.cl
}

diferenças, sobressai que as lesões intestinais se concentraram principalmente no íleo, os granulomas ocorreram com maior frequência nesta seção do intestino que no seu correspondente linfonodo. Além disso, nas lesões bacterianas, o infiltrado inflamatório linfonodos linfáticos era composta principalmente por macrófagos. Estas diferenças podem ser devidas a variações individuais dos animais, o estádio da doença ou de uma estirpe diferente do agente patogénico. Este estudo permitiu obter informação básica sobre a doença e descrever padrões de lesões encontradas em veados e em gamos com pré-diagnóstico, de paratuberculosis clínica nunca antes descritas na literatura.

TERMOS DE INDEXAÇÃO: Paratuberculose, veado vermelho, Cervus elaphus, gamo, Dama dama, Mycobacterium avium, veado, MAP.

\section{INTRODUCTION}

Paratuberculosis is a chronic disease caused by Mycobacterium avium subspecies paratuberculosis (MAP) that affects 
wild and domestic ruminants worldwide, and has been found in a wide variety of artiodactyles and perisodactyles (Ayele et al. 2001). This bacteria is an acid-fast bacilli (AFB), of 0.5-1.5 $\mu \mathrm{m}$ wide, Gram-positive, and it is described as an obligated intracellular pathogen. Its cellular wall is relatively permeable and rich in lipids. MAP is highly resistant to extreme conditions and it can survive months in the environment, and rainfall can increase its dissemination (Larsen et al. 1956, Twort \& Ingram 1912, Salgado et al. 2013).

The typical clinical signs in deer include weakness and chronic weight loss, diarrhea (liquid and green), and dingy, dry and hirsute fur (Manning et al. 1998). According to the severity of clinical signs the infection can be divided into four stages: silent stage, sub-clinical, clinical and advanced clinical (Whitlock \& Buergelt 1996). The silent stage is present in animals up to a year old, without any clinical signs of the disease. The subclinical phase occurs in adults and is characterized by lack of visible clinical signs. The clinical stage is characterized by weight loss with chronic intermittent diarrhea. Some deer are more resistant and can recover to the subclinical stage. Finally, the disease continues to the advanced clinical stage, where animals can be seen emaciated with profuse diarrhea and ventral edema, submandibular being the most obvious. Most of these animals die from dehydration or cachexia (Whitlock \& Buergelt 1996). Due to the relatively rapid development of infection in deer is established that they are particularly vulnerable to disease and could become a potential hazard to other susceptible species, both in captivity and wildlife (Williams et al. 1983, Balseiro et al. 2008). The organs most commonly affected are the small intestine and mesenteric LN (Balseiro et al. 2008). Thickening and roughening of the intestinal mucosa is usually observed and is not as prominent in wildlife animals as it is in animals in captivity (Quist et al. 2002). The lymphatic vessels of the serosa of the small intestine are prominent, pale and firm. Mesenteric LN appear larger and pale (Manning et al. 1998). Macroscopic liver lesion are very rare, but in some cases there are yellowish pigmented granulomas at the cutting surface (Mahmoud et al. 2002). It is common to find lesions unrelated to MAP in wildlife animals due to the wasting and immunosuppression, such as pneumonia and ascitis ( Quist et al. 2002, González et al. 2005).

In the histopathological examination of deer tissues, the primary target is the digestive system and adjacent lymphoid organs. The lamina propria of the jejunum, ileum, cecum and colon is generally observed mildly to heavily infiltrated by macrophages containing AFB in the cytoplasm. The same reaction is observed in the parenchyma of the liver and mesenteric LN, displacing and affecting the typical architecture of the organ (Manning et al. 1998, Crawford et al. 2006). Laminar appearance calcification centers have been observed in NL of MAP-infected deer, usually present in germinal centers or granulomas with no inflammatory reaction, yet associated with giant cells in many cases (Hunnam et al. 2011). Inflammatory infiltrate can be found in the mesenteric lymph vessels and in some extreme cases hypertrophy of smooth muscle can occur (Williams et al.
1983). In some cases there are microscopic granulomas on the liver or big encapsulated granulomas containing pigment granules (Mahmoud et al. 2002, Paredes et al. 2007, Pradenas et al. 2014). Atherosclerotic lesions in the heart and aorta have been described (Del-Pozo et al. 2013). The presence of MAP AFB can be seen in various organs with the Ziehl-Neelsen (Z-N) staining method (Manning et al. 1998).

The objective of this study was to describe paratuberculosis lesions in red deer (Cervus elaphus) and fallow deer (Dama dama) of hunting and venison production farms in Chile, with clinical and advanced clinical paratuberculosis.

\section{MATERIALS AND METHODS}

The selection of samples for this study was conducted through a purposive sampling and by convenience. Fourteen (14) red deer (Cervus elaphus) and nine (9) fallow deer (Dama dama) with prediagnosis of clinical paratuberculosis, from hunting or venison production farms from the Los Ríos and Los Lagos Regions in Chile were selected. Basic dissection instrumental was used in the necropsy and work was carried out under the biosafety standards set by the Institute of Animal Pathology of the Universidad Austral de Chile (Paredes \& Cubillos 1995). An optical microscope (Olympus CX41) was used for visualization of histological sections and the digital micrographs was obtained using a computer with the program Micrometrics Premium ${ }^{\circledR}$ TM (version 2.7) mounted on a digital camera (Olympus U-TVO.5xC-3) integrated on the microscope.

The animals were euthanized humanely, maintaining all the necessary safeguards and ensuring animal welfare. The euthanasia method was approved by the bioethical committee of the Universidad Austral de Chile, DID-2011-14. A systematic pathologic analysis was performed for each animal, sampling small intestine, liver and mesenteric LN, considering that in some cases it was not possible to have access to all organs (Paredes \& Cubillos 1995). Samples for histopathology were obtained and processed according to the protocol used at the Institute of Animal Pathology of the Universidad Austral de Chile (Luna 1968). Samples for genetic identification of the pathogen using rtPCR for MAP were submitted to an external lab, using a previously described protocol (Pradenas et al. 2014). In samples where granulomas, epiteloid macrophages and/or giant cells were observed, Z-N staining was performed for further evaluation, thus seeking the presence of AFB. An assessment of the most common injuries associated with paratuberculosis was performed, and findings such as congestion, inflammation, granulomas, calcifications, Langhans cells and presence of AFB were analyzed. These lesions were graduated semiquantitatively in 4 categories based on their severity, using a modified Buergelt's scale (Buergelt et al 2000): (0) no lesions, (1) minimal lesions, (2) mild lesions, (3) moderate lesions, (4) severe lesions, (A) autolysis and (N/O) not observed.

\section{RESULTS}

In all the samples a culture and an rtPCR were performed, being positive to MAP in all cases. The results of the culture and rtPCR are not shown in this paper.

The most important macroscopic findings were depletion or total absence of fatty deposits of subcutaneous tissue and internal organs. In the small intestine the most frequent findings were diffuse chronic enteritis, mainly in the jejunum and ileum. In the ileum the mucosa was thickened and with presence of brain-like creases. The intestinal 
contents in colon and rectum were of liquid consistency, moss green colour and sui generis odor. Some mesenteric lymphatic vessels were observed thickened and firm. Mesenteric LN were usually enlarged, pale and firm. In some animals the same findings were observed in the LN associated with the liver, lungs and reproductive tract. In the liver, whitish, elongated and firm foci were found in the capsule and the parenchyma. The bile ducts were firm, thick and with dark, hard and brown particulate material in the lumen. Some cases had mild hepatitis, shown by the protruding parenchyma at the cutting surface.

The histopathological examination of the small intestine showed that the severity of injuries increased towards the posterior regions, being the most severe in the ileum. The most common alterations were congestion in mucosa and submucosa, mononuclear inflammatory infiltrate in the lamina propria and granulomas in the corium. Less common injuries were eosinophilic infiltrate in the lamina propria, presence of Langhans cells in the lamina propria, edema and hemorrhage in mucosa and submucosa. Congestion occurred in 16 animals (69.6\%) and mostly located in the lamina propria. Inflammatory disorders were presented as generalized chronic enteritis with mononuclear exudate, characterized by large numbers of lymphocytes and macrophages mostly located in the submucosa and lamina propria. This alteration occurred in 20 animals (87\%) and the condition was exacerbated in vicinity of the Peyer's patches. Granulomas were observed at the lamina propria, submucosa and serosa, being the submucosa the most frequent location. This alteration occurred in 15 animals (65.2\%). When performing Z-N staining, most frequent injuries were paucibacillary. Z-N positive cases were 6 animals (26.1\%) (Fig.1, Table 1). The lesions that didn't show AFB but were concordant with paratuberculosis were catalogued as paucibacillary. No animal presented this alteration in mild degree. One animal presented a mild to moderate infiltrate of Langhans cells in the mucosa. Animals that had large numbers of eosinophils, correspond to those

Table 1. Types of lesions found by organ according to the degree of affection

\begin{tabular}{|c|c|c|c|c|c|}
\hline & Minimal & Mild & Moderate & Severe & Total \\
\hline \multicolumn{6}{|l|}{ Small Intestine } \\
\hline Congestion & 6 & 6 & 3 & 1 & 16 \\
\hline Inflammation & 5 & 7 & 4 & 4 & 20 \\
\hline Granulomas & 5 & 4 & 5 & 1 & 15 \\
\hline AFB & 1 & 0 & 1 & 4 & 6 \\
\hline \multicolumn{6}{|c|}{ Mesenteric Lymph Node } \\
\hline Congestion & 6 & 2 & 3 & 4 & 15 \\
\hline Inflammation & 2 & 7 & 4 & 2 & 15 \\
\hline Granulomas & 2 & 0 & 1 & 1 & 4 \\
\hline AFB & 2 & 1 & 0 & 4 & 7 \\
\hline \multicolumn{6}{|l|}{ Liver } \\
\hline Congestion & 2 & 3 & 8 & 0 & 13 \\
\hline Inflammation & 2 & 4 & 2 & 0 & 8 \\
\hline Granulomas & 2 & 2 & 1 & 2 & 7 \\
\hline
\end{tabular}
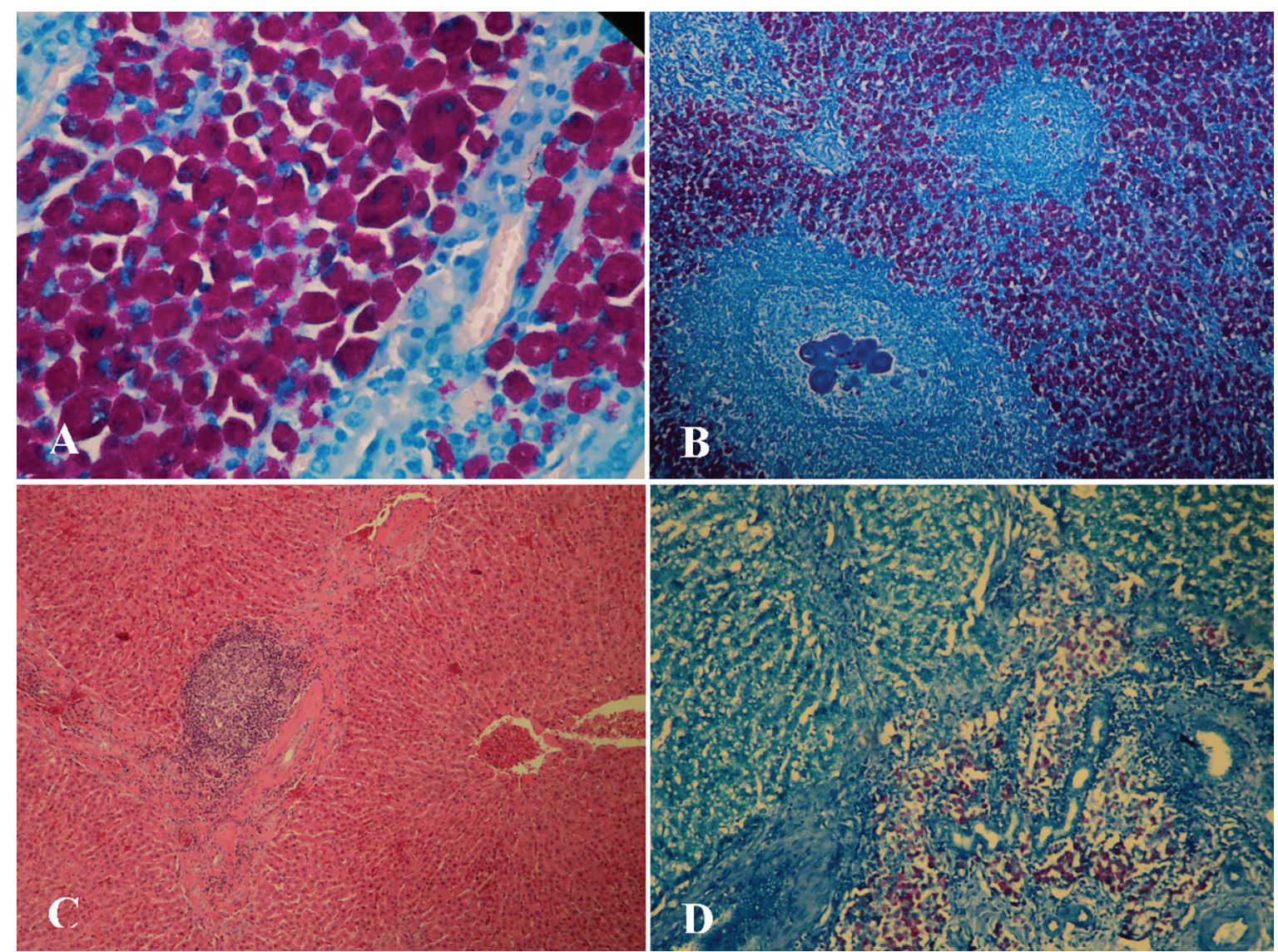

Fig.1. (A) Ileum, acid-fast bacilli (AFB) in macrophages in the lamina propria. (B) Mesenteric lymph node, AFB in macrophages in the cortex and laminar central calcification in a granuloma. (C) Liver, granuloma in a portal space. (D) Liver, AFB in macrophages in a portal space. 
with injuries attributable to parasitism by Fasciola hepati$c a$, lungworms concordant with Dictyocaulus viviparus or other unidentified digestive parasites.

In the mesenteric lymph nodes, the most frequent lesions observed were congestion in the cortex and paracortex, mononuclear inflammatory infiltrate in the cortex and granulomas. Other injuries were central calcifications found in granulomas, presence of Langhans cells in the cortex and paracortex and eosinophilic inflammatory infiltrate. The congestion was evident in the cortex and in the most severe cases this finding extended to the paracortex. Congestion was present in 12 cases (52.2\%). Inflammation was visualized as hyperplasia of cortical layer with proliferation and increased number of germinal centers, accompanied by inflammatory infiltrate composed of lymphocytes and macrophages and was found in 15 animals (65.2\%). Granulomas were found in 4 animals (17.4\%). Z-N staining showed 7 (30.4\%) positive animals (Fig.1, Table 1). The lesions that didn't show AFB but were concordant with paratuberculosis were catalogued as paucibacillary. Langhans cells were found in 6 animals $(26.1 \%)$, showing mild to severe infiltrations in the cortex, mainly surrounding granulomas or germinal centers. In 4 animals, central calcifications with laminar appearance in granulomas or germinal centers were found.

The histopathological examination of the liver showed very particular results. The most common lesions in the liver were congestion in the sinusoidal capillaries, portal vein, and centrilobular hepatic vein, mononuclear inflammatory infiltrate in portal tracts and trabeculae, and granulomas the portal tracts and trabeculae. In 13 animals $(56.5 \%)$, congestion in sinusoidal capillaries was seen. The inflammatory infiltrate contained mostly lymphocytes and macrophages restricted to the portal tracts and trabecular connective tissue, and it was present in 8 animals (34.8\%). Granulomas were found in portal tracts in 7 animals (30.4\%) (Fig.1, Table 1). These granulomas were often accompanied by Langhans cells. In 3 animals (13\%), AFB were observed inside and within the granulomas (Figure 1). The lesions that didn't show AFB but were concordant with paratuberculosis were catalogued as paucibacillary.

\section{DISCUSSION}

Regarding macroscopic findings, the depletion of fat deposits was found in all cases where a necropsy was performed. While this condition is shared by many diseases, it is widely described for clinical paratuberculosis (Williams et al 1983, Paredes et al 2007). Macroscopic lesions were observed mainly in the small intestine (jejunum and ileum) and mesenteric LN. Thickening of the intestinal wall and increase on the size of LN was the most commonly observed feature, consistent with the findings of Balseiro et al. (2008) and Pradenas et al. (2014). Williams et al. (1983) also coincides with the macroscopic findings in the LN, but reports that the intestine maintains a normal appearance without macroscopic alterations. Thickening of the mesenteric lymph vessels was a common finding in the current study and is consistent with the findings of Williams et al. (1983) and Paredes et al. (2007) who described their calci- fication. Balseiro et al. (2008) reported the absence of this condition, which could be due to differences in the animals because their study was conducted with wild deer. In the liver, the findings of whitish foci of firm consistency in the capsule and parenchyma, along with the thickened bile ducts and hard particulate material correspond to a parasitosis caused by Fasciola hepatica, while the clearer nodular parenchymal foci found at the cutting surface could be attributed to inflammatory infiltrate.

In the current research, the histopathological lesions frequently found in the affected organs (small intestine, liver and LN) were congestion, inflammatory infiltrate with lymphocytes, histiocytes and macrophages, granulomas, and presence of BAAR, corresponding to the findings of other authors (Williams et al. 1983, Balseiro et al. 2008, Woodbury et al. 2008, Hunnam et al. 2011, Del-Pozo et al. 2013). The intestinal lesions were concentrated in the most caudal portions of the small intestine, mainly in the ileum. The study of Balseiro et al. (2008) showed no clear difference between the sections of the small intestine, while Manning et al. (1998) points the jejunum as the most affected section. These differences may be due to the stage of the disease. The type of inflammatory infiltrate in the mucosa and submucosa of small intestine most commonly found in this study corresponded to diffuse mononuclear infiltrate mainly composed of lymphocytes and macrophages, consistent with the findings of other authors (Williams et al. 1983, Manning et al. 1998, Balseiro et al. 2008, Del-Pozo et al. 2013). The presence of Langhans cells in the intestine was a rare finding, contradicting the findings of Balseiro et al. (2008).

In the LN, the arrangement of the inflammatory infiltrate and granulomas is consistent with what is typically described in calves (Subharat et al. 2012). Follicular hyperplasia with increased numbers of germinal centers, which was also described by Williams et al. (1983) was presented. This situation is common in paratuberculosis but equally unspecific (Hunnam et al. 2011). The inflammatory infiltrate, consisting mostly of lymphocytes and macrophages, was also described by Williams et al. (1983) and Crawford et al. (2006). In the inflammatory infiltrate of the LN presenting AFB (6 cases) mostly macrophages were found, unlike the paucibacillary lesions or the ones attributed to other causes, in which lymphocytes predominated. Four of these cases were those with granulomas. This could be due to a reaction from macrophages to the multibacillary lesions and allows to conclude that the presence of large number of macrophages in the LN may be associated with the presence of AFB and the formation of granulomas. Calcifications of laminar appearance in some granulomas and germinal centers were observed, consistent with what was reported by other authors for this disease ( Williams et al. 1983, Balseiro et al. 2008, Hunnam et al. 2011). Of the 4 animals with calcifications, 3 had multibacillary injuries. The presence of granulomas was more commonly observed in the segment of intestine that its mesenteric lymph node, which differs from what was observed in the study of Hunnam et al. (2011), where the opposite was reported. 
Granulomas in the liver correspond to tuberculoid granulomas, they were multifocal and concentrated mainly in the trabecular connective tissue and portal tracts, different to the big pigmented granulomas (lepromatous granulomas) found in other study (Mahmoud et al. 2002). Tuberculoid granulomas are usually seen in more resistant individuals (Thomson 1988), which could imply that despite of the severe lesions and advanced state of disease, red and fallow deer in southern Chile tend to be resistant to MAP. The two cases in which the presence of granulomas in the liver was classified as severe, large amount of AFB were found in Z-N staining, which allows to suspect that the animals who showed less severe granulomas without AFB could be addressed as paucibacillary lesions. Del-Pozo et al. (2013) describes an unusual case of paratuberculosis in which multifocal granulomas were found in random arrangement within the parenchyma. Very few authors reported liver damage in paratuberculosis (Mahmoud et al. 2002, Paredes et al. 2007, Pradenas et al. 2014), probably because it is not considered a site of predilection for the disease. Only 3 animals showed AFB in the liver (cases 3.5 and 15).

Severe cases of clinical paratuberculosis, as the ones analyzed in this paper, are fairly common in Chile due to the lack of control programs and the reticence of most farmers to diagnose it. This situation has contributed to paratuberculosis spreads throughout the national territory and affects a large number of animals, in both production systems and wildlife. This study detected new findings related to paratuberculosis, helping to understand how the disease affects and how it manifests in this country and other countries with similar characteristics, and thus helps to improve the detection and eventual control of this disease.

\section{REFERENCES}

Ayele W., Machackova M. \& Pavlik I. 2001. The transmission and impact of paratuberculosis infection in domestic and wild ruminants. Veterinarni Medicina 46:205-224.

Balseiro A., García Marín J.F., Solano P., Garrido J.M. \& Prieto J.M. 2008. Histopathological classification of lesions observed in natural cases of paratuberculosis in free-ranging fallow deer (Dama dama). J. Comp. Pathol. 138:180-188.

Buergelt C.D., Layton A.W., Ginn P.E., Taylor M., King J.M., Habecker P.L., Mauldin E., Whitlock R., Rossiter C. \& Collins M.T. 2000. The pathology of spontaneous paratuberculosis in the North American bison (Bison bison). Vet. Pathol. 37:428-438.

Crawford G.C., Ziccardi M.H., Gonzales B.J., Woods L.M., Fischer J.K., Manning E.J. \& Mazet J.A. 2006. Mycobacterium avium subspecies paratuberculosis and Mycobacterium avium subsp. avium infections in a tule elk (Cervus elaphus nannodes) herd. J. Wildl. Dis. 42:715-723.

Del-Pozo J., Girling S., McLuckie J., Abbondati E. \& Stevenson K. 2013. An unusual presentation of Mycobacterium avium spp. paratuberculosis infection in a captive tundra reindeer (Rangifer tarandus tarandus). J. Comp. Pathol. 149:126-131.
González J., Geijo M.V., García-Pariente C., Verna A., Corpa J.M., Reyes L.E., Ferreras M.C., Juste R.A., García Marín J.F. \& Pérez V. 2005. Histopathological classification of lesions associated with natural paratuberculosis infection in cattle. J. Comp. Pathol. 133:184-196.

Hunnam J.C., Wilson P.R., Heuer C., Mackintosh C.G., West D.M. \& Clark R.G. 2011. Histopathology of grossly normal mesenteric lymph nodes of New Zealand farmed red deer (Cervus elaphus) including identification of lipopigment. Vet. Pathol. 48:525-529.

Larsen A.B., Merkal R.S. \& Vardaman T.H. 1956. Survival time of Mycobacterium paratuberculosis. Am. J. Vet. Res. 17:549-551.

Luna L. 1968. Manual of Histologic Staining Methods of the Armed Forces Institute of Pathology. 3rd ed. McGraw-Hill, New York.

Mahmoud O.M., Haroun E.M., Elfaki M.G. \& Abbas B. 2002. Pigmented paratuberculosis granulomata in the liver of sheep. Small. Rumin. Res. 43:211-217.

Manning E.J.B., Steinberg H., Rossow K., Ruth G.R. \& Collins M.T. 1998. Epizootic of paratuberculosis in farmed elk. J. Am. Vet. Med. Assoc. 213:1320-1322.

Paredes E. \& Cubillos V. 1995. Manual de Necropsia en Animales Domésticos y Envío de Muestras a Laboratorio. Uniprint, Imprenta Universitaria S.A., Valdivia, Chile.

Paredes E., Pradenas M., Kruze J., Jara M. \& Collins M. 2007. Pathological and bacteriological diagnosis of paratuberculosis in farmed red deer (Cervus elaphus) and fallow deer (Dama dama) in Chile. 9th Colloquium on Paratuberculosis, Tsukuba, Japan, p.161.

Pradenas M., Navarrete-Talloni M., Salgado M., Zambrano P. \& Paredes E. 2014. Paratuberculosis or avian tuberculosis in red deer with chronic diarrhea? Arch. Med. Vet. 46:45-52.

Quist C.F., Nettles V.F., Manning E.J., Hall D.G., Gaydos J.K., Wilmers T.J. \& Lopez R.R. 2002. Paratuberculosis in key deer (Odocoileus virginianus clavium). J. Wildl. Dis. 38:729-737.

Salgado M., Alfaro M., Salazar F., Troncoso E., Mitchell R.M., Ramirez L., Naguil A., Zamorano P. \& Collins M.T. 2013. Effect of soil slope on the appearance of Mycobacterium avium subsp. paratuberculosis in water running off grassland soil after application of contaminated slurry. Appl. Environ. Microbiol. 79:3544-3552.

Subharat S., Shu D., Wedlock D.N., Price-Carter M., De Lisle G.W., Luo D., Collins D.M. \& Buddle B.M. 2012. Immune responses associated with progression and control of infection in calves experimentally challenged with Mycobacterium avium subsp. paratuberculosis. Vet. Immunol. Immunopathol. 149:225-236.

Thomson R. 1988. Special Veterinary Pathology. Mosby Year-Book, Philadelphia, p.199-201.

Twort F.W. \& Ingram G.L. 1912. A Method for Isolating and Cultivating the Mycobacterium enteritidis chronicae pseudotuberculosae bovis Johne and some Experiments on the Preparation of a Diagnostic Vaccine for Pseudo-tuberculous Enteritis of Bovines. Proc. Royal. Society London 84:517-543.

Whitlock R.H. \& Buergelt C. 1996. Preclinical and clinical manifestations of paratuberculosis (including pathology). Vet. Clin. N. Am., Food. Anim. Pract. 12:345-356.

Williams E.S., Snyder S.P. \& Martin K.L. 1983. Pathology of spontaneous and experimental infection of North American wild ruminants with Mycobacterium paratuberculosis. Vet. Pathol. 20:274-290.

Woodbury M.R., Chirino-Trejo M. \& Mihajlovic B. 2008. Diagnostic detection methods for Mycobacterium avium subsp. paratuberculosis in white-tailed deer. Can. Vet. J. 49:683-688. 